\title{
Numerical investigation of stall characteristics for winglet blade of a horizontal axis wind turbine
}

\author{
Shalini Verma ${ }^{1 *}$, Akshoy Ranjan Paul ${ }^{1}$, Anuj Jain ${ }^{1}$, and Firoz Alam ${ }^{2}$ \\ ${ }^{1}$ Motilal Nehru National Institute of Technology Allahabad, Prayagraj, India \\ ${ }^{2}$ RMIT University, Melbourne, Victoria, Australia
}

\begin{abstract}
Wind energy is one of the renewable energy resources which is clean and sustainable energy and the wind turbine is used for harnessing energy from the wind. The blades are the key components of a wind turbine to convert wind energy into rotational energy. Recently, wingtip devices are used in the blades of horizontal axis wind turbine (HAWT), which decreases the vortex and drag, while increases the lift and thereby improve the performance of the turbine. In the present study, a winglet is used at the tip of an NREL phase VI wind turbine blade. Solidworks, Pointwise, and Ansys-Fluent are used for geometric modeling, computational grid generation, and CFD simulation, respectively. The computational result obtained using SST k- $\omega$ turbulence modeling is well validated with the experimental data of NREL at 5 and $7 \mathrm{~m} / \mathrm{s}$ of wind speeds. Numerical investigation of stall characteristics is carried out for wingleted blade at higher turbulence intensity (21\% and $25 \%)$ and angle of attack $\left(0^{0}\right.$ to $30^{\circ}$ at $5^{0}$ intervals) at $7 \mathrm{~m} / \mathrm{s}$ wind speed. The result found that wingletd blade delay stall to $15^{0}$ for both the cases of turbulence intensity. Increasing the turbulence intensity increases the lift coefficient at stall angle but drag coefficient also increases and thus a lower aerodynamic performance $\left(C_{L} / C_{D}\right.$ ratio $\left.=13\right)$ is obtained. Wingleted blade improves the performance as the intensity of vortices is smaller compared to baseline blade.
\end{abstract} Keywords. HAWT, Stall, Winglet, Turbulence intensity

\section{Introduction}

Greenhouse gas emissions from fossil fuels are one of the major environmental concerns. To reduce these emissions, it is necessary to avoid the use of fossil fuels. The environmental consequences of renewable sources are negligible and thus energy production from renewable sources is growing in a faster manner. Renewable energy sources like the wind are a cleaner option to generate electricity, therefore increasing the wind turbine installation. For improving the performance of wind turbines, the latest technique is to use blade tip devices that decrease the vortex, drag and increases the lift. Winglets are thus commonly used in aircraft and are considered to increase the efficiency of wind turbines. Dr. Whitcomb introduced the idea of winglet technology in July 1976 [1]. The most commonly used winglet is named as blended winglet and developed by Grazter from Seattle in 1994 [2]. This type of winglet is advantageous over other types due to the smooth curve and it reduces the interference drag at

\footnotetext{
*Corresponding author: shalini@mnnit.ac.in
}

the intersection of blade and winglet. Abdelghany et al., 2016; Gueraiche and Popov, 2017; Guerrero et al., 2018 $[3,4,5]$ have focused their study on the aerodynamic performance of winglets at varying cant angle. Khalafallah et al., 2019 [6] presented a parametric study of winglets using a CFD model including the winglet direction, cant angle, and twist angle and results suggested that adding winglets improves the performance of HAWT. Elfarra et al., 2015 [7] optimized the winglet design by varying cant angle and twist angle and found that optimized design produces $9 \%$ more power than baseline blade. Matheswaran and Miller, 2019 [8] also studied the effect of winglets on performance and suggested that the power coefficient increases $2.45 \%$. Considering these reviews, this paper includes the modern blended winglet with design parameters like cant angle, length of guide curve, and leading-edge sweep angle.

Since wind flow is three-dimensional, unsteady, and highly turbulent hence flow field around a wind turbine is complex. The natural wind has a variable speed and direction causing stall problems. In a turbulent flow field, the performance of HAWT is affected due to the stall phenomenon. These could not be prevented but it is necessary to understand the condition of occurrence and pattern of stall phenomenon. Stack, 1931[9] had discussed 
turbulence first time. He used a wind tunnel experiment to measure the lift and drag coefficient and suggested that turbulence increased the lift coefficient delaying stall. Later many researchers found that increased turbulence intensity delayed stall up to larger angle of attack [10,11,12]. The impact of turbulence results in a significant deviation in power output $[13,14]$. An experimental study on the aerodynamic behavior of an airfoil has been performed by varying turbulence levels and angle of attack. It is found that turbulence intensity has a strong impact on aerodynamic performance $[15,16]$. Sicot et al., 2006 [17] investigated the effect of turbulence intensity on HAWT aerodynamics. Experiments were done for different turbulence intensities and angles of attack. Results suggested that turbulence intensity has little effect on power coefficient, thrust coefficient, and drag coefficient but lift coefficient increases with turbulence intensity after $12^{0}$ angles of attack. Chu et al., 2014 [18] used a wind tunnel experiment to evaluate the turbulence effect on wake characteristics and performance of wind turbines. It is suggested that the turbulence effect can be neglected for high wind speed more than $8 \mathrm{~m} / \mathrm{s}$. Li et al., 2016(b) [19] also investigated the power performance for HAWT in a wind tunnel to examine the effect of turbulence intensity at the different conditions of blade pitch angles and yaw angles. Results suggested that blade pitch angle and yaw angle affect the performance of HAWT but turbulence intensity could be neglected. Li et al., 2016(c) [20] presented the effect of turbulence intensity on HAWT performance and suggested that for Re No. $\geq 1.5 \times 10^{5}$, there is a significant increase in lift coefficient at higher turbulence intensity and the drag coefficient is smaller in a turbulent flow field. The results also found that for lower turbulence intensity, flow separation occurs at the leading edge, and the separation region increases for turbulent flows. The literature reviews up till now reveal sufficient literature on airfoils investigating the effects of inflow turbulence intensity and stall phenomena using the experimental method. There is limited research on static stall phenomenon at varying turbulence intensity for the HAWT blade with winglet attached at the tip using CFD analysis. The stall phenomenon is a major concern in wind turbine development because the stall affects the flow on the blade surface and thereby affecting the power output of the wind turbine. It is important to study the stall phenomenon for HAWT blade having winglet at the tip for the safe running of a wind turbine for a long period.

The present study investigates the static stall phenomenon for NREL phase-VI wind turbine blades with and without adding blended winglets using CFD analysis. Class A type turbulence intensity $(21 \%$ and $25 \%)$ is used for the study. The angle of attack is varied $0^{0}-30^{0}$ at $5^{0}$ intervals. Lift and drag coefficient are analyzed for stall analysis and further flow characteristics are visualized in form of vorticity contour.

\section{Computational Methodology}

\subsection{Geometrical Model}

In this study, $19.8 \mathrm{~kW}$ rated power and $10.058 \mathrm{~m}$ rotor diameter wind turbine designed by NREL is used. The blade is tapered and twisted, modeled by S809 airfoil. The blade chord and blade twist are considered as per NREL specification [21]. The cut-in wind speed is $6 \mathrm{~m} / \mathrm{s}$ with 72 rpm rotational velocity. In the context of modification of the blade, a blended winglet is used at the tip of the blade to improve the power coefficient of the wind turbine. For modeling the blended winglet at the tip of the blade, cant angle $20^{\circ}$ with constant value as $30^{\circ}$ for leading-edge sweep angle is taken. For a smooth transition from blade to winglet tip, symmetric airfoil NACA 0018 is used at the tip of the blade. The SolidWorks model for blade without and with blended winglet at the tip is shown in fig. 1 and 2 .

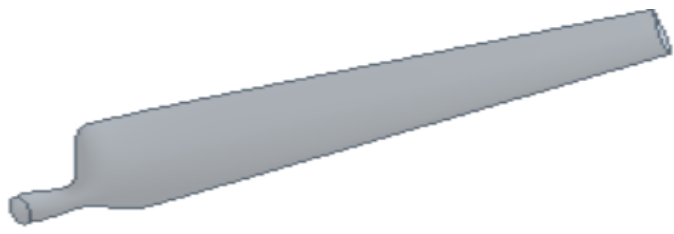

Fig. 1. Baseline blade

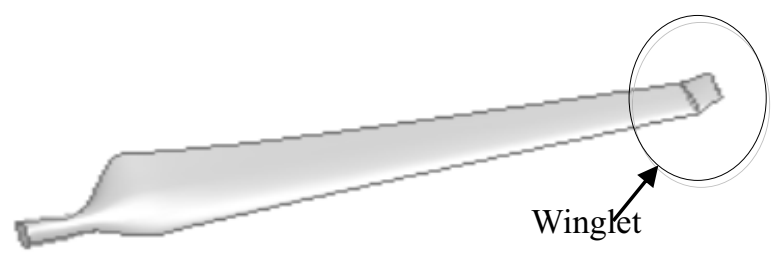

Fig. 2. Blade with winglet

\subsection{Computational domain with Boundary conditions}

The semi-cylindrical computational domain as shown in the figure has been used for CFD analysis of wind turbine blade aerodynamics. This half-cylindrical domain reduces the computational effort by modeling the blade with $180^{\circ}$ periodic boundary conditions. The domain is with $16 \mathrm{R}$ length and $8 \mathrm{R}$ radius, where $\mathrm{R}$ is the length of the blade. The blade is placed at a distance of 6R from the inlet. For this simulation, the computational domain and boundary conditions used are shown in figure 3. The domain consists of an inlet, outlet, no-slip wall, two periodic interfaces. The inlet is given as a velocity inlet in the direction of wind flow $(+Y)$. The outlet is assigned as a pressure outlet. The upper surface is the no-slip wall and the bottom two surfaces are considered as interfaces. 


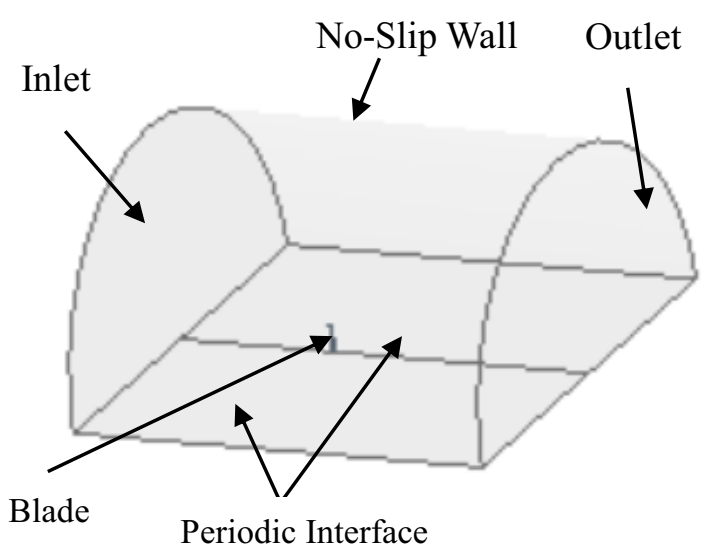

Fig. 3. Domain with boundary condition

\subsection{Grid generation}

For CFD analysis, pointwise software is used for hybrid mesh generation. For the blade surface, dimensions are 200 and 200 along chord length and spanwise respectively. For better quality, spacing is 0.002 and 0.01 at the leading and trailing edge respectively. In this paper, the first surface spacing from the blade is $5 \times 10^{-5} \mathrm{~m}$ with a growth rate of 1.2 and 20 layers around the blade. Fig. 4 shows the mesh on the computational domain and blade.

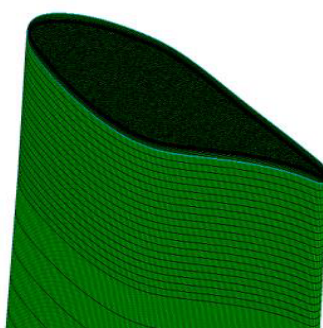

(a)

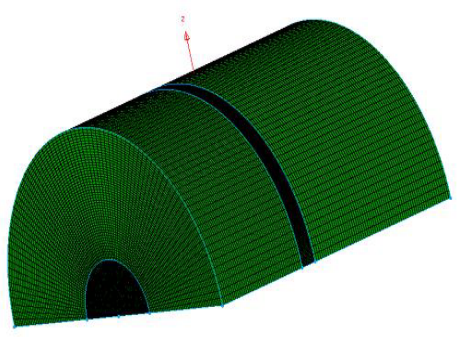

(b)

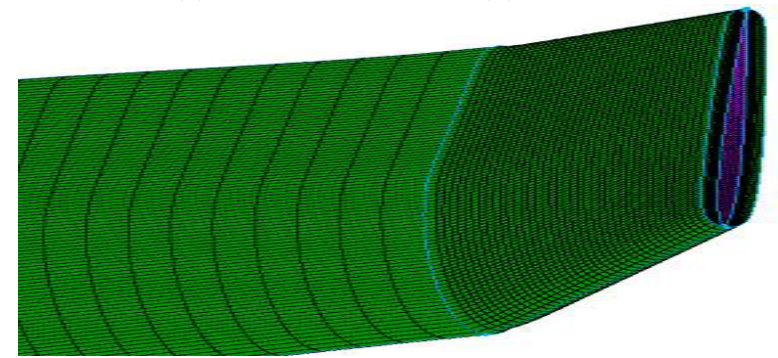

(c)

Fig. 4. Grid generation (a) near baseline blade (b) Domain (c) near winglet blade

A grid independency test is performed to get appropriate elements for a better solution of CFD analysis. The power performance of wind turbines is computed at a different number of elements as shown in figure 5 .

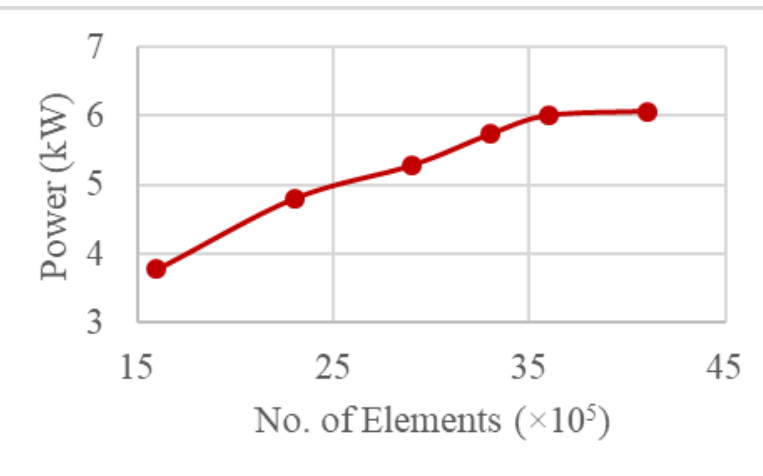

Fig. 5. Grid independency test (Power vs number of elements)

\subsection{Governing Equation and turbulence model}

\subsubsection{Navier-Stokes equation}

For fluid flow modeling, solving continuity equation and Navier-Stokes equation predicts the velocity and pressure for the geometry. For incompressible fluids, the Continuity equation is

$\nabla \cdot \vec{V}=0$

Navier-Stokes equation is as follows

$\rho \frac{d \vec{V}}{\partial t}+\rho(\vec{V} \cdot \nabla) \vec{V}=-\nabla p+\mu \nabla^{2} \vec{V}+\rho \vec{g}$

\subsubsection{SST k- $\omega$ turbulence model}

Transfer of the most turbulent shear stress is under consideration during this model by adjusting the turbulent viscosity. This model is surpassing in investigating the viscous near-wall space and in its accounting for the effects of gradients of streamwise pressure in boundarylayer flow. The equation for $\mathrm{k}$ and $\omega$ in eqs. 3 and 4 are written considering turbulence kinetic energy, dissipation due to turbulence, diffusion, and source terms.

$$
\frac{\partial(\rho k)}{\partial t}+\frac{\partial\left(\rho k u_{i}\right)}{\partial x_{i}}=\frac{\partial}{\partial x_{j}}\left(\Gamma_{k} \frac{\partial k}{\partial x_{j}}\right)+G_{k}-Y_{k}+S_{k}
$$

$\frac{\partial(\rho \omega)}{\partial t}+\frac{\partial\left(\rho \omega u_{i}\right)}{\partial x_{i}}=\frac{\partial}{\partial x_{j}}\left(\Gamma_{\omega} \frac{\partial \omega}{\partial x_{j}}\right)+G_{k}-Y_{\omega}+D \omega+S_{\omega}$

Effective diffusivities are given by considering turbulent Prandtl numbers for $\mathrm{k}$ and $\omega$ 


$$
\begin{aligned}
& \Gamma k=\mu+\frac{\mu_{t}}{\sigma_{k}} \\
& \Gamma \omega=\mu+\frac{\mu_{t}}{\sigma_{\omega}}
\end{aligned}
$$

\subsubsection{Simulation Setup}

The data for the property of air is given as density 1.225 $\mathrm{kg}-\mathrm{m}^{-3}$ and dynamic viscosity $1.7894 \times 10^{-5} \mathrm{~kg}-\mathrm{m}^{-1} \mathrm{~s}^{-1}$. The moving reference frame is used for blade rotation and rotation speed is $72 \mathrm{rpm}$ with $(0,0,0)$ rotation center and $(0$, $-1,0)$ as the rotation axis. The SIMPLEC algorithm was used for pressure-velocity coupling.

\section{Results and discussion}

\subsection{CFD Validation}

Validation of CFD result is done with experimental data of NREL at $5 \mathrm{~m} / \mathrm{s}$ and $7 \mathrm{~m} / \mathrm{s}$ Normal and thrust force coefficient are the parameters used for validation. The normal and thrust force coefficientis calculated using Eq. (7) and (8):

Normal Force Coefficient,

$$
C_{n}=\sum_{i=1}^{\text {\#oftaps }}\left(\frac{C_{P_{i}}+C_{P_{i+1}}}{2}\right)\left(x_{i+1}-x_{i}\right)
$$

Tangential Force Coefficient,

$$
C_{t}=\sum_{i=1}^{\text {\#oftaps }}\left(\frac{C_{P_{i}}+C_{P_{i+1}}}{2}\right)\left(y_{i+1}-y_{i}\right)
$$

where, $x_{i}=$ distance along chord line from leading edge to $\mathrm{i}^{\text {th }}$ pressure tap.

$\mathrm{Y}_{\mathrm{i}}=$ Distance from chord line along an axis orthogonal to chord to $\mathrm{i}^{\text {th }}$ pressure tap.

$\mathrm{C}_{\mathrm{pi}}=$ Pressure coefficient at $\mathrm{i}^{\text {th }}$ pressure tap.

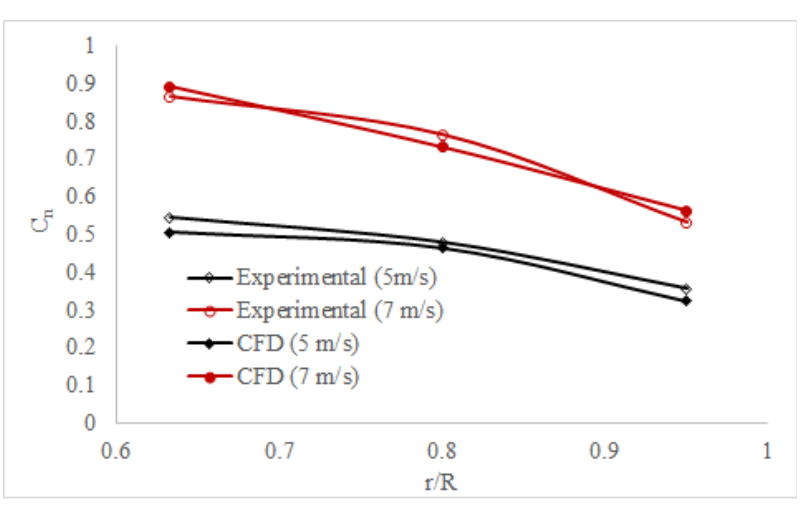

Fig. 6. Spanwise normal force coefficient
Figure 6 shows a variation of $C_{n}$ with radial distances $r / R$ as $0.633,0.80$, and 0.95 . At $5 \mathrm{~m} / \mathrm{s}$, a higher deviation of $9 \%$ at 0.95 while the minimum deviation of $3 \%$ at 0.80 radial span of the blade. At $7 \mathrm{~m} / \mathrm{s}$, the maximum and minimum error is $2 \%$ and $6 \%$ at 0.633 and 0.95 radial distance respectively.

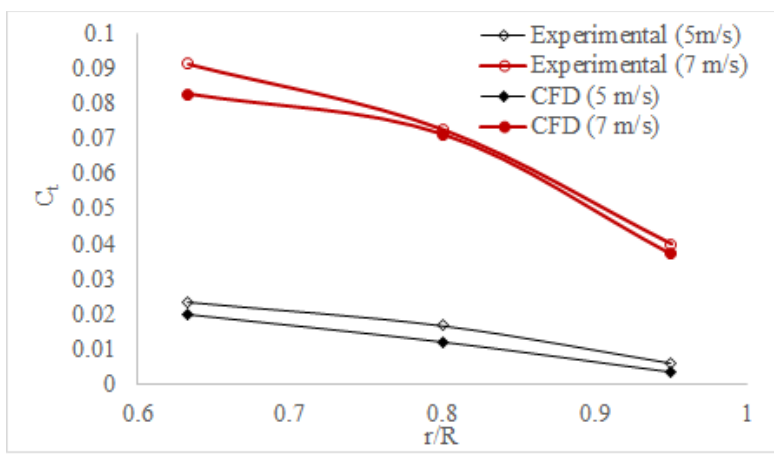

Fig. 7. Spanwise tangential force coefficient

\subsection{Effect of Inflow Turbulence and Winglet on Static stall}

For stall analysis lift and the drag coefficient is calculated using Eq. (9) and (10).

$$
\begin{gathered}
C_{L}=C_{n} \cos \alpha+C_{t} \sin \alpha \\
C_{D}=C_{n} \sin \alpha-C_{t} \cos \alpha
\end{gathered}
$$

At five radial distances of blade span $(30 \%, 47 \%, 63 \%$, $80 \%$, and $95 \%$ ), the $\mathrm{C}_{\mathrm{n}}$ and $\mathrm{C}_{\mathrm{t}}$ values are calculated through pressure coefficient and then $C_{L}$ and $C_{D}$ value are computed for five radial distances at a different angle of attack $\left(0^{\circ}-30^{\circ}\right)$. To calculate $C_{L}$ and $C_{D}$ value for the blade, averaging is done using the weighting factor. The weighting factor for $30 \%, 47 \%, 63 \%$, and $80 \%$ is considered as unit span while for $95 \%$ it is $3 / 4$ of unit span [22].

In figure 8 , it can be observed that $\mathrm{C}_{\mathrm{L}}$ is approximately linearly increasing with increasing $\mathrm{AOA}$ from $0^{\circ}$ to $5^{\circ}$ for both cases. For baseline blade stall angle is $10^{\circ}$ while for the wingleted blade it is delaying and the stall is at $15^{\circ}$. By increasing the turbulence intensity, $\mathrm{C}_{\mathrm{L}}$ is increasing with $\mathrm{AOA}$ and $5 \%$ higher at stall angle compared to lower turbulence intensity. For the baseline blade case, the increase in $\mathrm{C}_{\mathrm{L}}$ is smaller for $21 \%$ and $25 \%$ turbulence intensity. After $10^{0}$ angles of attack, $\mathrm{C}_{\mathrm{L}}$ is higher for wingleted blades in both cases of turbulence intensity. 


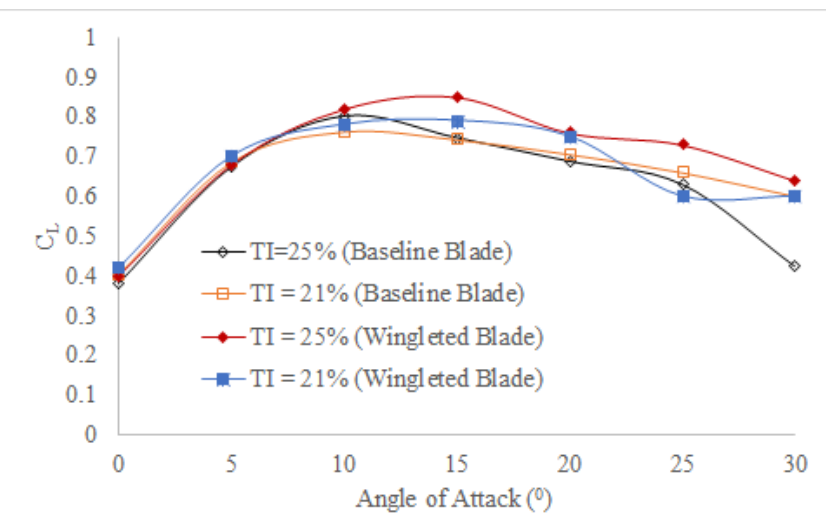

Fig. 8. Lift coefficient at the varying angle of attack for baseline blade and wingleted blade

From figure 9, it is observed that initially, $\mathrm{C}_{\mathrm{D}}$ is increasing at a smaller rate with AOA. There is a lesser difference in $\mathrm{C}_{\mathrm{D}}$ for baseline blade and wingleted blade till $5^{\circ}$. This is due to the higher skin friction coefficient as the blade surface has increased after adding winglet at the tip. $C_{D}$ increases rapidly after stall angle. After $5^{\circ} \mathrm{AOA}$, a difference in $C_{D}$ is visible for baseline and wingleted blade. At higher turbulence intensity $C_{D}$ is higher compared to lower turbulence intensity.

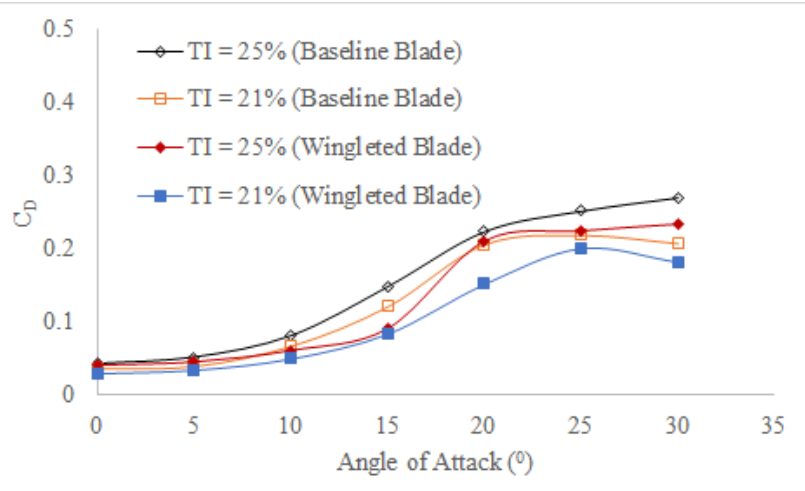

Fig. 9. Drag coefficient at the varying angle of attack for baseline blade and wingleted blade

Overall aerodynamic performance can be seen in figure 10 of $C_{L} / C_{D}$ ratio. For baseline blade, a higher value of $C_{L}$ is at $10^{0}$ for $25 \%$ turbulence intensity but at the same time, there is also maximum drag. Thus, maximum $C_{L} / C_{D}$ ratio is 13 which is $23 \%$ less compared to $21 \%$ turbulence intensity. Aerodynamic performance is better for $21 \%$ turbulence intensity and wingleted blade compared to other cases.

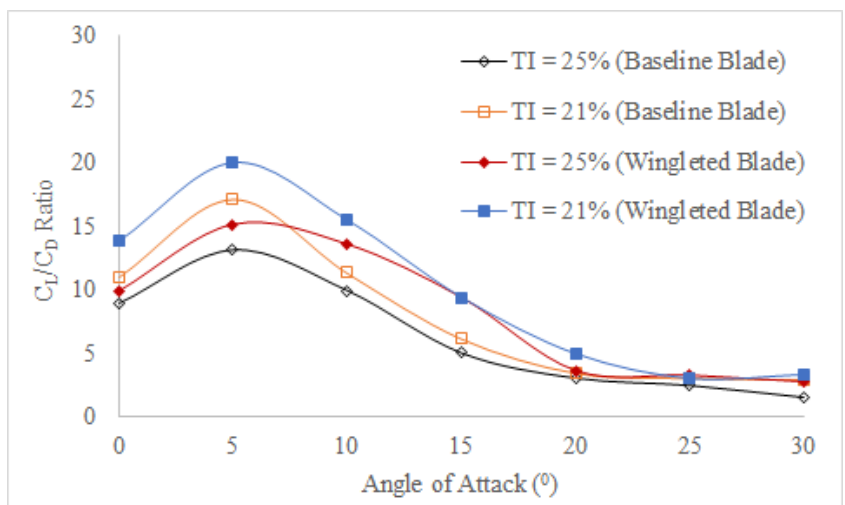

Fig. $10 . C_{L} / C_{D}$ ratio at the varying angle of attack for baseline blade and wingleted blade

\subsection{Flow Visualization downstream of the blade}

The tip vortices for $5^{\circ}$ and $10^{\circ} \mathrm{AOA}$ is observed at $21 \%$ and $25 \%$ TI for baseline and winglet case through $Q$ criterion level of 0.003 . The velocity curl contour is plotted at different planes locating at downstream of the tip of the blade. The intensity of velocity curl is maximum at the center and reduces far away from the center. From figure 11 and 12, it can be observed that wingleted blade tip vortices dissipate faster for $5^{\circ} \mathrm{AOA}$ and TI $21 \%$ as the intensity of velocity curl are reducing far away from the tip. It is observed that for the same AOA and turbulence intensity, the vortices for the wingleted blade are smaller compared to the baseline blade.
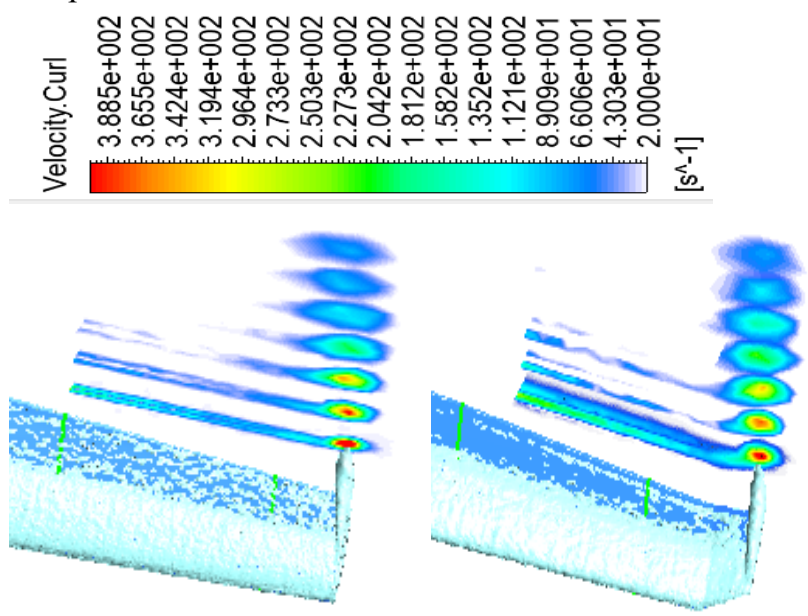

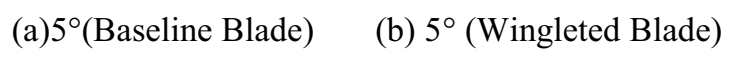



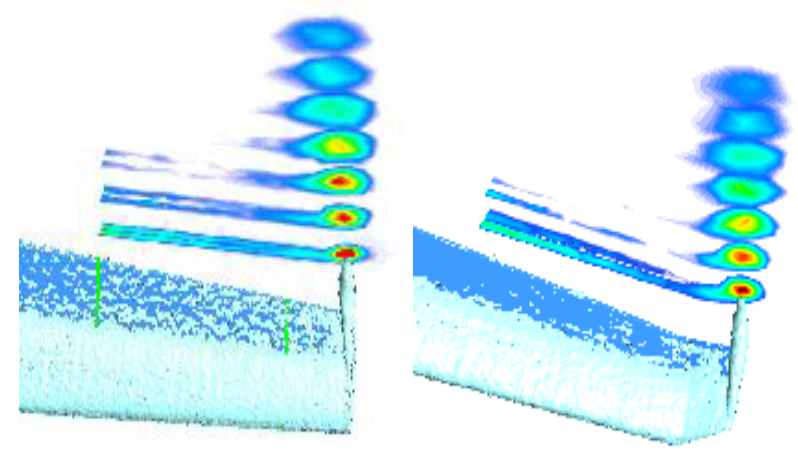

(c) $10^{\circ}$ (Baseline Blade) (d) $10^{\circ}$ (Wingleted Blade)

Fig. 11. Tip vortices pattern for $21 \%$ turbulence intensity
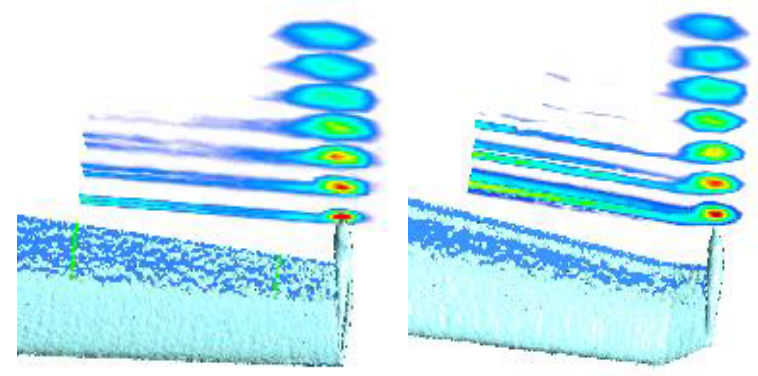

(a) $5^{\circ}$ (Baseline Blade)

(b) $5^{\circ}$ (Wingleted Blade)
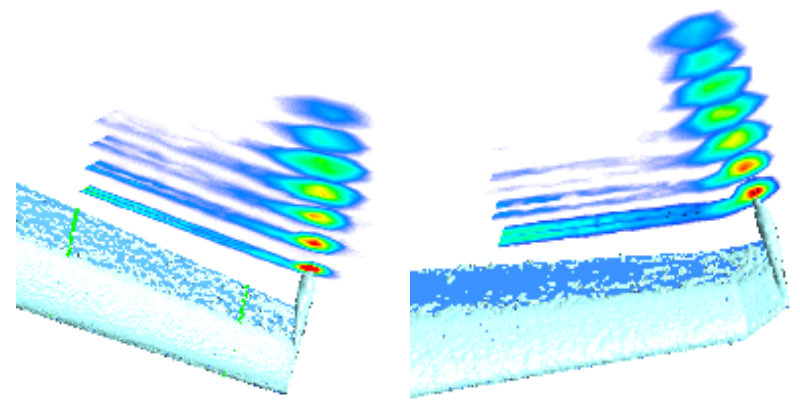

(a) $10^{\circ}$ (Baseline Blade) (b) $10^{\circ}$ (Wingleted Blade)

Fig. 12. Tip vortices pattern for $25 \%$ turbulence intensity

\section{Conclusions}

Higher turbulence intensity and wingleted blades are tested for stall occurrence in the study. A winglet is added at the tip of the NREL phase VI wind turbine blade. $C_{n}$ and $C_{t}$ are used as a parameter for validation of CFD result with the experimental result of NREL. It is concluded that

- For the baseline blade, the stall angle is at $10^{\circ}$ AOA while it is $15^{\circ}$ for the wingleted blade.

- For higher turbulence intensity, $\mathrm{C}_{\mathrm{L}}$ is higher at stall angle compared to lower turbulence intensity.

- With the increasing turbulence intensity drag coefficient also increases and decreases its overall aerodynamic performance.

- Higher $C_{L} / C_{D}$ ratio is found for wingleted blades at $21 \%$ turbulence intensity.
- With increasing AOA, the intensity of vortices is increasing but it dissipates faster for wingleted blade case.

The study carried out in this paper is limited to management of static stall. For dynamic stall, the aerodynamic characteristics of the blades would necessary be different [23] and management of the same could be an interesting topic for further research.

\section{References}

1. R.T. Whitcomb, A design approach and selected wind tunnel results at high subsonic speeds for wing-tip mounted winglets. NASA TN D-8260. Natl. Aeronaut. Space Admin: Washington, DC, USA (1976)

2. L.B. Gratzer, Blended winglet, ed: Google Patents (1994)

3. E.S. Abdelghany, E.E. Khalil, O.E. Abdellatif, G. Elhariry, Aircraft winglet design and performance: Cant angle effect, in 14th International Energy Conversion Engineering Conference, Salt Lake City, UT (2016)

4. D. Gueraiche, S. Popov, Aerospace, 4(4), 60 (2017)

5. J. Guerrero, M. Sanguineti, K. Wittkowski, Aerospace, 5(4), 126 (2018)

6. M.G. Khalafallah, A.M. Ahmed, M.K. Emam, Advances in Mechanical Engineering, 11(9), 1687814019878312 (2019)

7. M.A. Elfarra, N.S. Uzol, I.S. Akmandor, Investigations on blade tip tilting for HAWT rotor blades using $C F D$, International journal of green energy, 12(2), 125-138 (2015)

8. V. Matheswaran, L.S. Miller, In AIAA, 1297 (2019)

9. J. Stack, Tests in the variable density wind tunnel to investigate the effects of scale and turbulence on airfoil characteristics, National Advisory Committee for Aeronautics, 364 (1931)

10. K.E. Swalwell, J. Sheridan, W.H. Melbourne, The effect of turbulence intensity on stall of the NACA 0021 aerofoil, in 14th Australasian fluid mechanics conference, 10-14 (2001)

11. M. Seddighi, M. Soltani, The influence of free stream turbulence intensity on the unsteady behavior of a wind turbine blade section, in 45th AIAA Aerospace Sciences Meeting and Exhibit, 630 (2007)

12. V.H. Maldonado, The role of free stream turbulence and blade surface conditions on the aerodynamic performance of wind turbine blades (2012)

13. D.L. Elliott, J.B. Cadogan, Effects of wind shear and turbulence on wind turbine power curves, PNL-SA18354, CONF-900989-2 (1990)

14. Y. Sheinman, A. Rosen, A dynamic model of the influence of turbulence on the power output of a wind turbine, Journal of Wind Engineering and Industrial Aerodynamics, 39(1-3), 329-341 (1992) 
15. P. Devinant, T. Laverne, J. Hureau, Journal of Wind Engineering and Industrial Aerodynamics, 90(6), 689707 (2002)

16. X. Amandolese, E. Szechenyi, Experimental study of the effect of turbulence on a section model blade oscillating in stall. Wind Energy: An International Journal for Progress and Applications in Wind Power Conversion Technology, 7(4), 267-282 (2004)

17. C. Sicot, P. Devinant, T. Laverne, S. Loyer, J. Hureau, Experimental study of the effect of turbulence on horizontal axis wind turbine aerodynamics, Wind energy, 9(4), 361-370 (2006)

18. C.R. Chu, P.H. Chiang, Journal of Wind Engineering and Industrial Aerodynamics, 124, 82-89 (2014)

19. Q.A. Li, J. Murata, M. Endo, T. Maeda, Y. Kamada, Energy, 113, 713-722 (2016 b).
20. Q.A. Li, Y. Kamada, T. Maeda, J. Murata, Y. Nishida, Energy, 111, 701-712, (2016 c)

21. M.M. Hand, D.A. Simms, L.J. Fingersh, D.W. Jager, J.R. Cotrell, S. Schreck, S.M. Larwood, National Renewable Energy Lab., Golden, CO.(US). NREL/TP-500-29955 (2001)

22. J. Tangler, D. Kocurek, Wind turbine post-stall airfoil performance characteristics guidelines for blade-element momentum methods, in 43rd AIAA Aerospace Sciences Meeting and Exhibit, 591 (2005)

23. P. BLV Ramana, A.R. Paul, A. Jain, K. Matsuura, Computational study on dynamic stall and flow control in a pitching airfoil, in Proceedings of 16th Asian Congress of Fluid Mechanics, 1-10 (2021) 